\title{
Impact of a pharmaceutical care incentive program on the asthma medication ratio among pediatric patients with persistent asthma enrolled in a Medicaid program
}

\author{
José J Hernández-Muñoz, PhD; Chandni R Kamdar, PharmD Candidate; Lixian Zhong, PhD; \\ Joy Alonzo, ME, PharmD; and Lisa Sprenger, PharmD, BCPS
}

\section{What is already known about this subject}

- Asthma is one of the leading chronic disease states in pediatric patients in Texas.

- Texas Health Service Region 11 (HSR 11) has the third-highest number of Medicaid pediatric beneficiaries with asthma; however, the region's average medical reimbursement per beneficiary is the second-lowest of the 11 health service regions.

- Pharmacy-led interventions are associated with improved quality of care among individuals with chronic diseases.

\section{What this study adds}

- This study estimated a prevalence of asthma medication utilization of $14.55 \%$ among Medicaid pediatric beneficiaries in Texas HSR 11 in 2018-2019.

- This study showed that the prevalence of pharmaceutical care incentive $(\mathrm{PCI})$ program interventions among Medicaid pediatric beneficiaries with at least 1 asthma medication claim during the study period was $1.70 \%$.

- This study found that the mean asthma medication ratio (AMR) for beneficiaries with persistent asthma was 0.50 ; however, the adjusted mean AMR in the $\mathrm{PCl}$ intervention group (0.530) compared with the nonintervention group (0.483) was not statistically significant.

\section{Author affiliations}

José J Hernández-Muñoz, PhD, and Lixian

Zhong, PhD, Pharmaceutical Sciences

Department, Irma L. Rangel College of Pharmacy, Texas A\&M University, College Station. Chandni R Kamdar, PharmD Candidate, Pharmaceutical Sciences Department and Pharmacy Practice Department, Irma L. Rangel College of Pharmacy, Texas A\&M University, College Station. Joy Alonzo, ME, PharmD, Pharmacy Practice Department, Irma L. Rangel College of Pharmacy, Texas A\&M University, College Station. Lisa Sprenger, PharmD, BCPS, Driscoll Health Plan, Corpus Christi, TX.

AUTHOR CORRESPONDENCE: José J Hernández-Muñoz, 979.436.0656; jhern001@tamu.edu

J Manag Care Spec Pharm. 2021;27(6):714-23

Copyright $\odot 2021$, Academy of Managed Care Pharmacy. All rights reserved.

service in their medication utilization and asthma medication ratio (AMR).

(PCI) programs on Texas Medicaid pediatric beneficiaries.

OBJECTIVES: To (1) describe the prevalence of asthma medication utilization and persistent asthma among Medicaid pediatric patients in Texas Health Service Region 11 (HSR 11) and (2) describe the prevalence and impact of $\mathrm{PCl}$ program interventions offered by pharmacists to Medicaid pediatric patients or their caregivers at the point-of-
METHODS: This study used a 2-year longitudinal assessment of Medicaid pharmacy claims for beneficiaries aged between 0 and 18 years, with continuous enrollment, and at least 1 asthma medication claim during 2018 and 2019. The prevalence of asthma medication utilization during the study period was described. Also, 
the prevalence of $\mathrm{PCl}$ interventions among beneficiaries with at least 1 asthma medication was described. The prevalence of $\mathrm{PCI}$ interventions was also estimated for beneficiaries with persistent asthma. The AMR for beneficiaries with persistent asthma was calculated and compared for those with and without at least $1 \mathrm{PCl}$ intervention.

RESULTS: 22,051 beneficiaries with continuous enrollment between the ages of 0 and 18 years and with at least 1 pharmacy claim for an asthma medication during the study period were included. The overall prevalence of asthma medication utilization was $14.55 \%$.

$374(1.70 \%)$ beneficiaries with at least 1 asthma medication received at least 1 asthma $\mathrm{PCl}$ intervention. Among beneficiaries that received at least 1 asthma $\mathrm{PCl}$ intervention, 158 (42.25\%) were on rescue medication only; 4 (1.07\%) were on maintenance medication only; and $212(56.68 \%)$ were on rescue and maintenance medications. The overall prevalence of persistent asthma was $4.86 \% .52$ (0.76\%) persistent asthma cases received at least 1 asthma $\mathrm{PCI}$ intervention after the index date. The overall unadjusted mean AMR (SD) for the 6,885 beneficiaries with persistent asthma was 0.50 (0.19). The adjusted AMR (SD) among beneficiaries with persistent asthma was reported at $0.530(0.026)$ for beneficiaries who received at least $1 \mathrm{PCl}$ intervention and $0.483(0.002)$ for beneficiaries who did not receive a $\mathrm{PCl}$ intervention $(P=0.066)$. Beneficiaries with persistent asthma generated $64.35 \%$ of the total asthma pharmacy claims during 2019.

CONCLUSIONS: Despite a high utilization of asthma medications among Medicaid pediatric beneficiaries, pharmacists servicing this group are underusing the $\mathrm{PCl}$ program interventions. An increase in the AMR among patients with persistent asthma receiving $\mathrm{PCI}$ interventions was observed when compared with those without $\mathrm{PCl}$ interventions. However, the difference was not statistically significant. Subsequent studies should include larger groups of beneficiaries receiving $\mathrm{PCl}$ interventions to establish the effect of $\mathrm{PCI}$ interventions on AMR before widespread implementation.

Asthma is a chronic respiratory disease that affects the airways in the lungs. Patients with asthma may present with shortness of breath, coughing, wheezing, chest tightness, fatigue, or anxiety. Disease severity ranges from mild with intermittent episodes to severe with persistent symptoms that may occur throughout the day and affect patient quality of life. ${ }^{1}$ Asthma has created an unbearable economic burden on society. In 2013, the total estimated cost associated with asthma, including medical care, missed school, missed work, and mortality, was over $\$ 81.90$ billion. $^{2}$ Asthma currently has no cure; however, evidence-based asthma management guidelines have been well established to control the symptoms and improve quality of life. ${ }^{3}$

In 2019, the Centers for Disease Control and Prevention reported that asthma affected $7.80 \%$ of children under the age of 18 years in the United States, where the most recent crude rate per 10,000 population of hospitalizations and emergency department (ED) visits were 4.50 and 104.70, respectively, in the same age group. ${ }^{4}$ The state of Texas is one of the highest-ranking states for childhood asthma prevalence among Medicaid enrollees (12.97\%). ${ }^{5}$ As of 2020 , Medicaid and the Children's Health Insurance Program (CHIP) provided health care benefits to $3,707,183$ children in Texas. ${ }^{6}$ The Texas Department of Health and Human Services reported that $7.00 \%$ of the children in Texas had a diagnosis of asthma during 2016. The Rio Grande Valley and the southern portion of the Gulf Coast (ie, Health Service Region 11 [HSR11]) had the third highest number of Medicaid pediatric patients diagnosed with asthma. However, the HSR11 average reimbursement per beneficiary was the second lowest out of the 11 regions. A potential underutilization of services, suboptimal continuity of care, or lack of coordination of health care services among pediatric patients with asthma in HSR11 may explain this phenomenon. ${ }^{7}$

The active involvement of health care providers, patients, and caregivers plays an essential role in managing medical conditions such as pediatric asthma. ${ }^{8-10}$ Pharmacist-led cognitive interventions have proven to be valuable tools to improve health services utilization and outcomes in pediatric patients with asthma. ${ }^{11,12}$ The pharmaceutical care incentive (PCI) programs are examples of managed care initiatives that sponsor pharmacist-led interventions.

The purpose of a PCI program intervention is to improve patient medication utilization and adherence by providing educational services when patients or their caregivers pick up their prescriptions. Pharmacists who provide the PCI interventions are reimbursed for the services as a function of their time and service type. HSR 11 recently implemented a PCI service program. However, no study has described the prevalence of PCI use nor the impact of PCI program interventions on asthma medication utilization and asthma control measures among Medicaid pediatric beneficiaries in HSR 11.

The purpose of this study was to describe asthma medication utilization patterns among Medicaid pediatric patients in Texas HSR 11 during 2018 and 2019. This study also compared medication utilization among patients receiving or not receiving PCI program interventions during the study period. The impact of receiving or not receiving PCI interventions on the asthma medication ratio (AMR) among patients with persistent was also compared. 


\section{FIGURE 1 Counties Serviced by the Managed Care Organization}

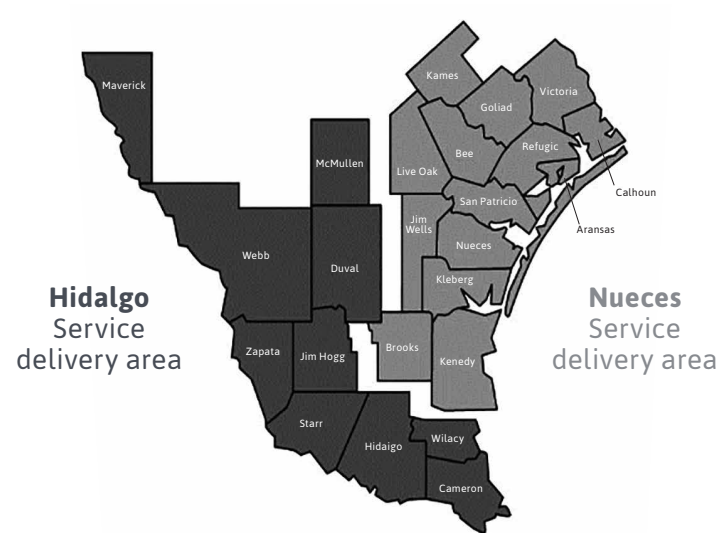

\section{Methods}

\section{STUDY DESIGN}

This study used a 2-year longitudinal assessment of pharmacy claims from a managed care organization (MCO) in Texas HSR11 that cared for Medicaid pediatric patients.

\section{STUDY SAMPLE AND VARIABLES}

The study sample included beneficiaries with continuous enrollment from January 1, 2018, to December 31, 2019, who were aged between 0 and 18 years and had at least 1 pharmacy claim for asthma medication. Beneficiaries with a 30-day gap or less in coverage during the study period were classified as continuous enrollment. The MCO serves beneficiaries from 24 counties in the South Texas Region (Figure 1).

Generic Product Identifier (GPI) codes were used to identify and classify the pharmacy claims as maintenance or rescue medications, based on the MCO's drug formulary. The maintenance medication group included inhaled corticosteroids (ICSs), combined ICSs plus long-acting $§ 2$-agonists, long-acting anticholinergics, longacting 1 2-agonists, and leukotriene receptor antagonists. Included rescue medications were inhaled short-acting ß2-agonists, anticholinergic bronchodilators, and combinations of $\mathrm{S} 2$-agonist and anticholinergic bronchodilators (Supplementary Table 1, available in online article). The PCI is a reimbursement program for outpatient network pharmacies that provide in-person cognitive service to the MCO beneficiaries. Payment to the pharmacy for the service is conducted through online adjudication of a PCI claim using specific NationalDrugCodenumbers(SupplementaryTable2, available in online article). Qualifying activities for PCI reimbursement included formulary exchange (\$4 per prescription), therapeutic interchange (\$12 per prescription), change in dose (\$5 per prescription), patient compliance monitoring services (\$10 per prescription or encounter), and patient training (\$1 per minute). Although PCI interventions are not unique to asthma, in this study we identified PCI interventions that were linked to prescriptions for asthma medication.

The unweighted AMR ([the number of controller medication claims] $\div$ [number of controller medication claims + number of rescue medication claims]) was used to classify asthma control among beneficiaries with persistent asthma. ${ }^{13-15}$ The AMR is an accurate predictor of patient-centered and health outcomes among adults and children with asthma. ${ }^{15-17}$ Of the MCO drug formulary maintenance therapies, ICSs, combined ICSs plus long-acting B2-agonists, and leukotriene receptor antagonists were considered controller medications. The range of values for the AMR runs from $0-1$, with 0 indicating the worst possible control and 1 indicating the best control possible. Previous studies have dichotomized the AMR into at least 0.50 or less than 0.50 , where values less than 0.50 are considered predictors of increased health care utilization. ${ }^{16,18}$

Other variables included in this study were the beneficiary's age, sex, and number of different pharmacies visited to fill asthma medications during the study period. Age was calculated using the date of the last asthma medication claim during the study period, and it was dichotomized for the AMR analysis. School-age beneficiaries were defined as aged at least 5 years, and nonschool age was less than 5 years. The Institutional Review Board approved the study protocol.

\section{PREVALENCE OF ASTHMA MEDICATION UTILIZATION}

The overall prevalence of asthma medication utilization was estimated by dividing the total number of beneficiaries with at least 1 pharmacy claim for asthma medication by the average number of pediatric beneficiaries per month during the study period. The proportion of beneficiaries with at least 1 pharmacy claim for asthma medication in each of 6 mutually exclusive medication groups was compared during the study period. The 6 groups were as follows: (1) beneficiaries with rescue medication claims only; (2) beneficiaries with maintenance medication claims only; (3) beneficiaries with rescue and maintenance medication claims; (4) beneficiaries with rescue medication and asthma PCI claims; (5) beneficiaries with maintenance medication and asthma PCI claims; and (6) beneficiaries with rescue, maintenance, and asthma PCI claims. 


\section{FIGURE 2 Algorithm Used to Define Beneficiaries with Persistent Asthma}

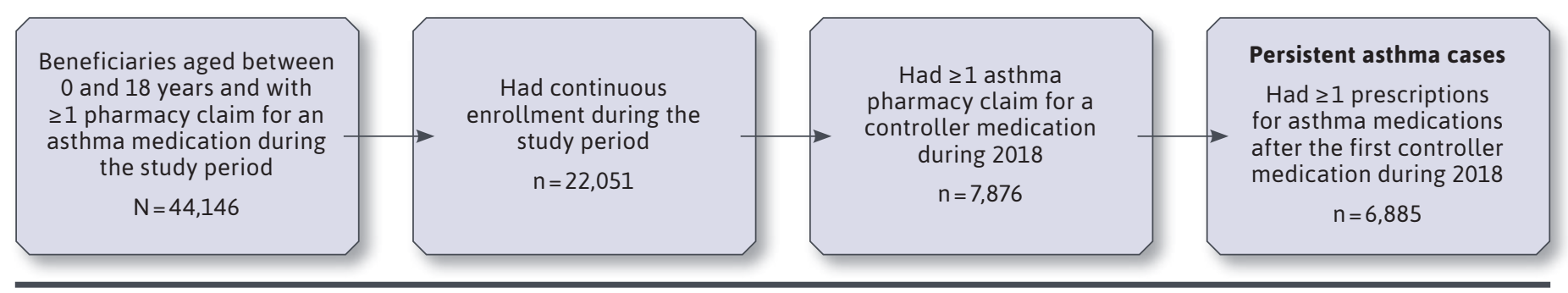

\section{PREVALENCE OF PCI INTERVENTIONS AMONG BENEFICIARIES USING ASTHMA MEDICATIONS}

The prevalence of asthma PCI interventions was estimated by dividing the total number of beneficiaries with at least 1 asthma PCI intervention by the number of pediatric beneficiaries with at least 1 asthma medication during the 2 years. The prevalence of at least 1 PCI intervention was also calculated for beneficiaries within the rescue medication only, a maintenance medication only, and rescue and maintenance medication groups. The proportion of beneficiaries with rescue medication only, maintenance medication only, and rescue and maintenance medications among those with at least 1 PCI intervention was also calculated.

\section{PREVALENCE OF PERSISTENT ASTHMA}

Current asthma guidelines recommend reserving treatment with controller medication for patients with persistent asthma. ${ }^{19}$ Therefore, in this study, persistent asthma cases were defined as those with at least 1 controller medication claim during 2018 and at least 1 asthma medication claim on a subsequent date during 2018 or 2019. The first pharmacy claim for a controller medication during 2018 was classified as the index date. After the index date, a follow-up asthma medication requirement was put in place to ensure a more robust AMR estimate for each beneficiary. Pharmacy claims from 2019 were not used to identify persistent asthma cases to provide at least 365 days of follow-up data after the index date. The prevalence of persistent asthma during 2018 was estimated by dividing the total number of beneficiaries with persistent asthma by the average number of pediatric beneficiaries per month during 2018.

\section{PREVALENCE OF PCI INTERVENTIONS AMONG BENEFICIARIES WITH PERSISTENT ASTHMA}

The prevalence of asthma PCI interventions among beneficiaries with persistent asthma during the study period was estimated by dividing the total number of beneficiaries with at least $1 \mathrm{PCI}$ intervention after the index date by the number of pediatric beneficiaries with persistent asthma.

\section{AMR AMONG BENEFICIARIES WITH PERSISTENT ASTHMA}

The AMR was calculated for each beneficiary with persistent asthma. Only pharmacy claims that occurred after the index date were used to calculate the AMR. The overall mean for the AMR among beneficiaries with persistent asthma was reported. The mean AMR among beneficiaries with and without at least 1 asthma PCI intervention after the index date was calculated and compared. The mean AMR was also compared by the beneficiaries' age group, sex, and the number of unique pharmacies visited to get asthma medications.

\section{TRENDS IN ASTHMA MEDICATION UTILIZATION}

A time trend chart was used to describe the monthly number of pharmacy claims for asthma medications among pediatric beneficiaries of the MCO with continuous enrollment for 2018 and 2019. The monthly number of asthma medication claims for pediatric beneficiaries with persistent asthma during 2019 was also described.

\section{STATISTICAL ANALYSIS}

The mean and SD were used to describe variables that followed a normal distribution. A visual analysis of each variable distribution and the Shapiro Wilk test were used to test for normality. The median and the interquartile range (IQR) were used to describe variables that followed a non-normal distribution. The Student t-test was used to compare the means for variables that followed a normal distribution, and the Mann-Whitney U test was used to compare the medians for variables with a non-normal distribution between 2 independent groups. The Spearman's rank correlation test was used to summarize the strength and direction of the relationship between 2 ordinal variables or between an ordinal and a continuous variable. The chi-square test was 


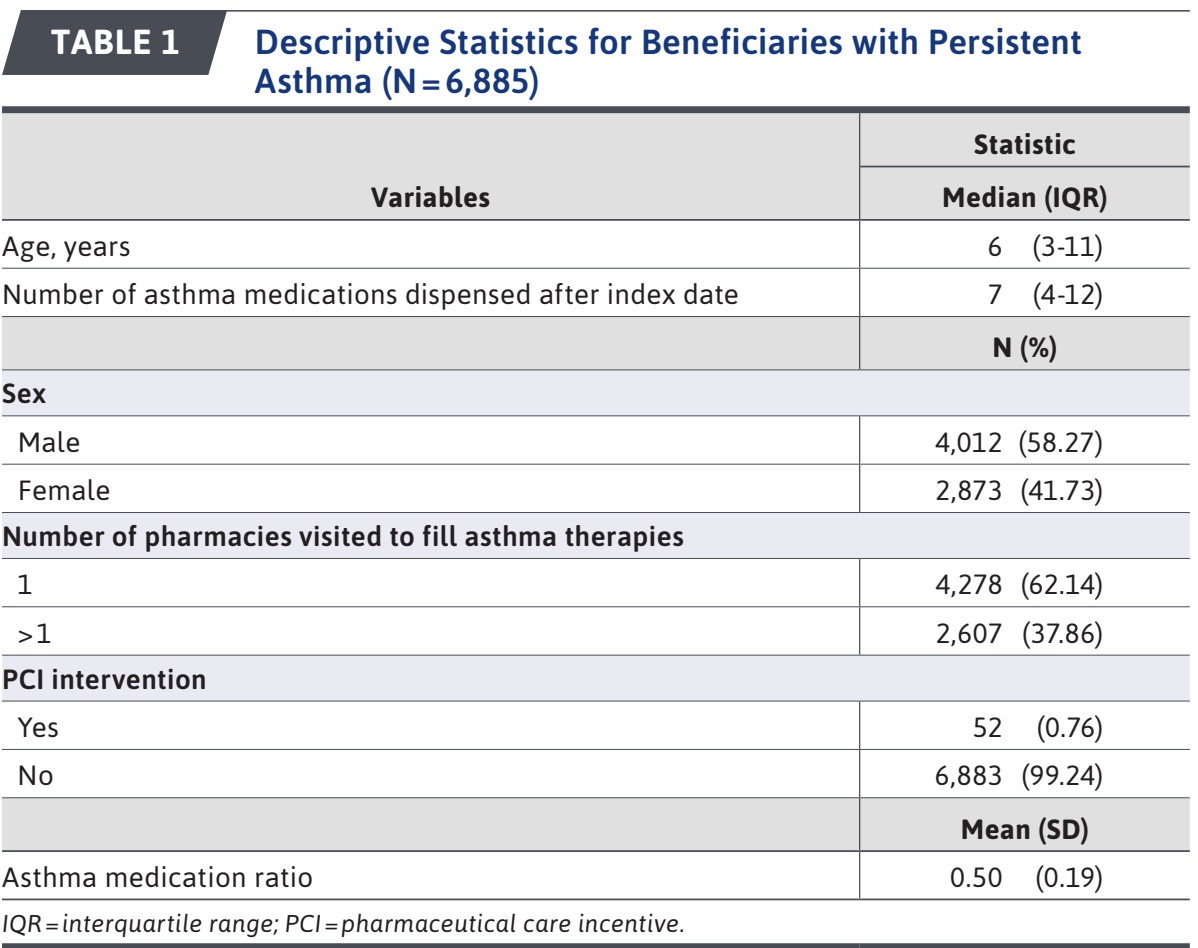

used to compare the proportion of individuals at each level of 2 variables when both were measured categorically. A general linear model and the corresponding least-squares mean and standard error (SE) were used to compare the adjusted AMR for each study variable. Statistical analysis was conducted using SAS version 9.4 (SAS Institute), and $P$ values of 0.05 or less were considered statistically significant.

\section{Results}

\section{PREVALENCE OF ASTHMA MEDICATION UTILIZATION}

A total of 44,146 beneficiaries aged between 0 and 18 years with at least 1 pharmacy claim for an asthma medication during the study period were identified. Of these beneficiaries, 22,051 (49.95\%) fulfilled the inclusion criteria of continuous enrollment during the 2 years (Figure 2). The 22,051 beneficiaries had a median (IQR) age of 6 (3-11) years, and 12,072 (54.75\%) were male. The median (IQR) number of asthma medications dispensed per beneficiary was 3 (2-6), and 15,937 (72.27\%) beneficiaries visited the same pharmacy to get all of their asthma medications during the study period. Based on the definition of at least 1 pharmacy claim for an asthma medication, the overall prevalence of asthma medication utilization was 14.55\%. Among beneficiaries with at least 1 pharmacy claim for asthma, 13,044 (59.15\%) received rescue medication only, 274 (1.24\%) maintenance medication only, 8,359 (37.91\%) rescue and maintenance medication only, 4 $(0.02 \%)$ maintenance medication and asthma PCI intervention, 158 (0.72\%) rescue medication and asthma PCI intervention, and 212 (0.96\%) rescue, maintenance, and asthma PCI interventions.

\section{PREVALENCE OF PCI INTERVENTIONS AMONG BENEFICIARIES USING ASTHMA MEDICATIONS}

Of the beneficiaries with at least 1 asthma medication, 374 (1.70\%) received at least 1 asthma PCI intervention. School-age beneficiaries were more likely to experience a PCI intervention than beneficiaries who were not school age $(P<0.001)$. Beneficiaries with at least 1 asthma PCI intervention had a median of 6 asthma medication claims during the study period, and those without an asthma PCI intervention had $3(\mathrm{P}<0.0001)$. There was no statistically significant difference in the likelihood of having asthma PCI interventions by sex $(P=0.110)$ or the number of pharmacies visited $(P=0.146)$. Among the beneficiaries who received rescue medication only, 158 (1.21\%) received at least 1 asthma PCI intervention; among those who received maintenance medication only, $4(1.46 \%)$ received at least 1 asthma PCI intervention; and among those who received rescue and maintenance medications, 212 (2.54\%) received at least 1 asthma PCI intervention $(\mathrm{P}<0.001)$. Also, among beneficiaries who received at least 1 asthma $\mathrm{PCI}$ intervention, 158 (42.25\%) were on rescue medication only; 4 (1.07\%) were on maintenance medication only; and 212 (56.68\%) were on rescue and maintenance medications.

\section{PREVALENCE OF PERSISTENT ASTHMA}

There were 7,876 pediatric patients with at least 1 asthma pharmacy claim for a controller medication during 2018. Of these 7,876 beneficiaries, $6,885(87.42 \%)$ had at least 1 prescription for an asthma medication after the index date (Figure 2). The 6,885 pediatric beneficiaries were classified as persistent asthma cases. Based on the definition used in this study, the overall prevalence of persistent 
TABLE 2 Unadjusted and Adjusted Analysis for the Mean AMR Scores Among Beneficiaries with Persistent Asthma $(\mathrm{N}=6,885)$

\begin{tabular}{|c|c|c|c|c|}
\hline \multirow[b]{2}{*}{ Variables } & \multicolumn{2}{|c|}{ Unadjusted } & \multicolumn{2}{|c|}{ Adjusted } \\
\hline & Mean (SE) & P value & LS-mean (SE) & P value \\
\hline \multicolumn{5}{|l|}{$\mathrm{PCl}$} \\
\hline Yes & $0.548 \quad(0.026)$ & \multirow{2}{*}{0.052} & $0.530 \quad(0.026)$ & \multirow{2}{*}{0.066} \\
\hline No & $0.497 \quad(0.002)$ & & $0.483 \quad(0.002)$ & \\
\hline \multicolumn{5}{|l|}{ Number of pharmacies } \\
\hline$>1$ & $0.465 \quad(0.004)$ & \multirow{2}{*}{$<0.001$} & $0.482 \quad(0.013)$ & \multirow{2}{*}{$<0.001$} \\
\hline 1 & $0.517 \quad(0.003)$ & & $0.531 \quad(0.013)$ & \\
\hline \multicolumn{5}{|l|}{ Sex } \\
\hline Male & $0.495 \quad(0.003)$ & \multirow{2}{*}{0.194} & $0.504 \quad(0.013)$ & \multirow{2}{*}{0.151} \\
\hline Female & $0.501 \quad(0.004)$ & & $0.510 \quad(0.013)$ & \\
\hline \multicolumn{5}{|l|}{ Age group, years } \\
\hline$\geq 5$ & $0.526 \quad(0.003)$ & \multirow{2}{*}{$<0.001$} & $0.540 \quad(0.013)$ & \multirow{2}{*}{$<0.001$} \\
\hline$<5$ & $0.450 \quad(0.004)$ & & $0.473 \quad(0.013)$ & \\
\hline Number of asthma therapies & $0.002^{\mathrm{a}}$ & $<0.001$ & $0.002^{\mathrm{a}}$ & $<0.001$ \\
\hline
\end{tabular}

aMean change in AMR by a unit increment in asthma therapies.

$A M R=$ asthma medication ratio; $L S=$ least squares; $P C l=$ pharmaceutical care incentive; $S E=$ standard error.

asthma during 2018 was $4.65 \%$. Among the beneficiaries with persistent asthma, the median (IQR) age was 6 (3-11) years, and 4,012 (58.27\%) were male. The median (IQR) number of asthma medications dispensed per beneficiary after the index date was 7 (4-12), and 4,278 (62.14\%) visited the same pharmacy to get all of their asthma medications during the study period (Table 1).

\section{PREVALENCE OF PCI INTERVENTIONS AMONG BENEFICIARIES WITH PERSISTENT ASTHMA}

Of the beneficiaries with persistent asthma, $52(0.76 \%)$ received at least 1 asthma PCI intervention after the index date. There was no statistically significant difference in the likelihood of receiving $\mathrm{PCI}$ interventions by age group $(P=0.889)$, sex $(P=0.932)$, or the median number of asthma medication claims during the study period
$(P=0.241)$. However, visiting a single pharmacy to fill all asthma medications was statistically associated with a higher likelihood of receiving asthma PCI services $(P=0.027)$.

\section{AMR AMONG BENEFICIARIES WITH PERSISTENT ASTHMA}

The mean (SD) AMR for the 6,885 beneficiaries with persistent asthma was $0.50(0.19)$. The unadjusted mean (SE) AMR among beneficiaries with persistent asthma was 0.548 (0.026) and 0.497 (0.002) for those with and without an asthma PCI intervention. Although the mean AMR was higher among beneficiaries who received at least 1 asthma PCI intervention, the difference was not statistically significant $(P=0.052)$.

The unadjusted mean (SE) AMR for beneficiaries with persistent asthma and of school age was $0.526(0.003)$ and $0.450(0.004)$ for those younger than school age $(\mathrm{P}<0.0001)$. Also, there was a statistically significant difference in the unadjusted mean (SE) AMR for beneficiaries using the same pharmacy to get their asthma medications (0.517 [0.003]) as compared with those using at least 1 pharmacy $(0.465$ [0.004]; $P<0.0001)$.

Similarly, there was a positive correlation between the mean AMR and the median number of asthma claims $(P<0.0001)$. The difference in AMR by sex was not statistically significant $(P=0.194)$. In the adjusted model, using the same pharmacy to get all asthma medications $(\mathrm{P}<0.0001)$, being in the school-age group $(P<0.0001)$, and having a higher number of pharmacy claims for asthma $(P<0.0001)$ were associated with higher mean AMR values. However, receiving at least 1 asthma $\mathrm{PCI}$ intervention $(\mathrm{P}=0.066)$ and $\operatorname{sex}(P=0.151)$ were not statistically significant (Table 2).

\section{TRENDS IN ASTHMA MEDICATION UTILIZATION}

A similar trend in the absolute monthly number of asthma medication claims was observed among pediatric beneficiaries of the MCO with continuous enrollment for 2018 and 2019. The highest number of asthma medication claims was observed for January and February during both years. However, for December, the absolute number of asthma medication claims decreased by 1,544 in 2019 compared with 2018 (Figure 3). The shapes for the monthly number of pharmacy claims for asthma medications for beneficiaries with at least 1 asthma medication claim and persistent asthma during 2019 were similar. Although persistent asthma cases represented only $31.22 \%$ of the beneficiaries with at least 1 asthma medication claim during the study period, their asthma claims represented $64.35 \%$ of the total asthma claims during 2019. 


\section{FIGURE 3 Absolute Number of Pharmacy Claims for Asthma per Month for 2018 and 2019 and the Percentage of These That Were Generated by Persistent Asthma Cases During 2019}

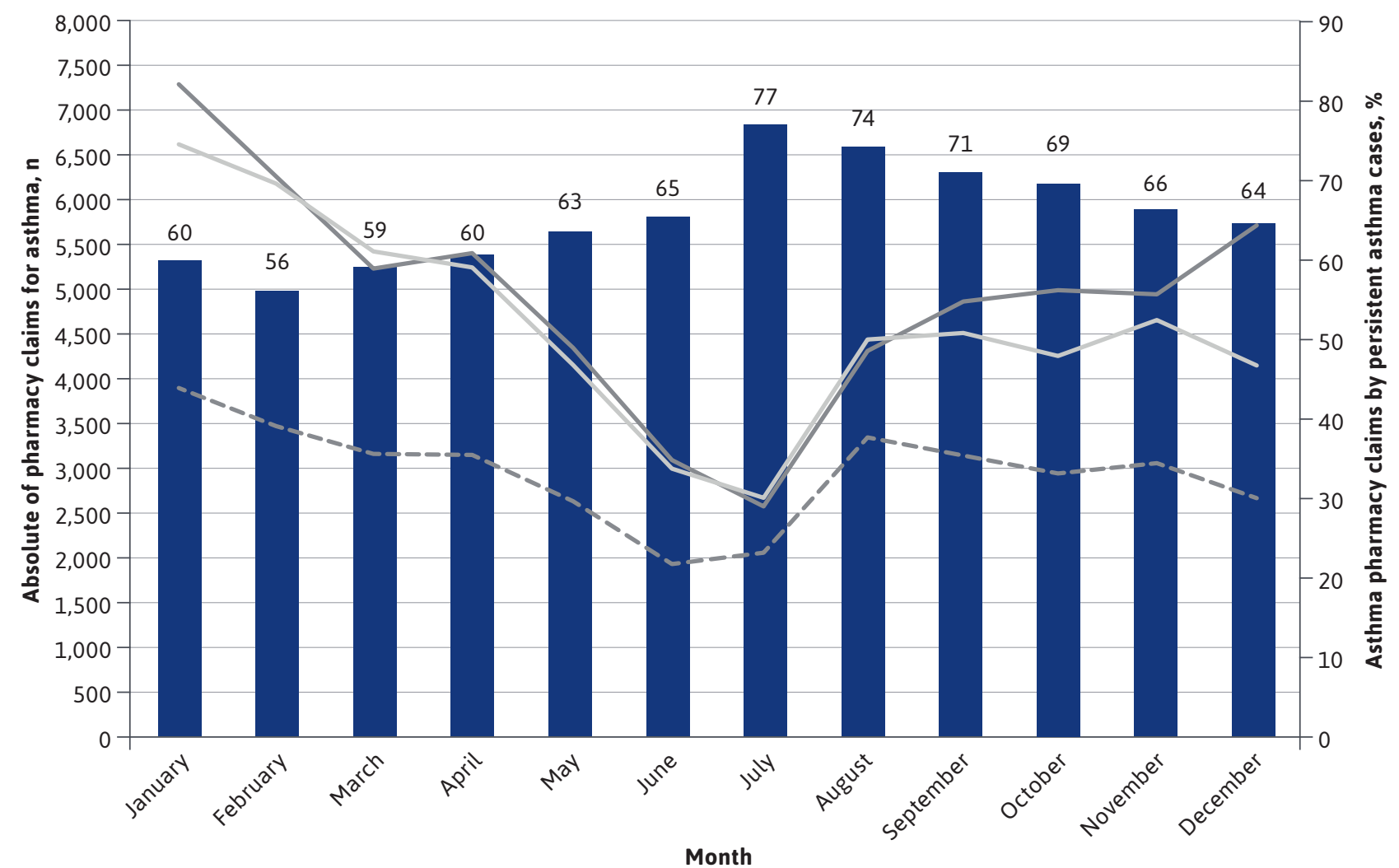

$\%$ of the overall \# of pharmacy claims for asthma generated by persistent asthma cases during 2019

\# of asthma medication claims generated by all beneficiaries during 2018

\# of asthma medication claims generated by all beneficiaries during 2019

- - \# of asthma medication claims generated by persistent asthma cases during 2019

\section{Discussion}

In the United States, the highest prevalence of asthma among Medicaid-enrolled children is within the southern Midwest region, which includes Texas. ${ }^{5}$ Texas HSR 11 had the third highest proportion of pediatric beneficiaries with asthma care inpatient hospitalizations, outpatient hospitalizations, or physician visits in the Texas Medicaid program during 2014 (17.64\%). ${ }^{7}$ However, no asthma prevalence data have been reported for HSR 11 since 2013. ${ }^{20}$ Our study reported a prevalence of asthma medication utilization of $14.55 \%$ among Medicaid pediatrics beneficiaries in HSR 11 plus 4 counties from HSR 8 (ie, Karnes, Goliad, Victoria, and Maverick).
The estimated prevalence of asthma medication utilization in our study is slightly higher than the reported prevalence of asthma using medical and pharmacy claims data among Medicaid pediatric patients in the state of Texas (13.00\%). ${ }^{5}$ This finding suggests that using pharmacy claims for asthma medication could serve as an excellent proxy to estimate asthma prevalence. Previous studies have reported a positive predictive value of $91 \%$ when using asthma pharmacy claims to identify asthma cases. ${ }^{21}$

In our study, the median number of asthma medications dispensed per beneficiary during the 2 years was 3 , and 8,571 (38.87\%) beneficiaries received rescue and maintenance medications during the study period. Therefore, the use of primary care services and the appropriate preventive 
care pharmacotherapies for asthma may be suboptimal. In fact, despite having the third highest proportion of asthma care inpatient hospitalizations, outpatient hospitalizations, or physician visits of all Texas public health regions during 2014, HSR 11 had the second lowest average reimbursement per beneficiary with asthma (\$246.30).?

Our study also found that of all the beneficiaries with at least 1 asthma medication during the 2-year study period, 374 (1.70\%) received PCI program interventions when filling their asthma prescriptions. Therefore, future studies should be designed to increase awareness and use of reimbursable cognitive services by pharmacists when dispensing asthma prescriptions.

The estimated prevalence of persistent asthma in our study (4.65\%) was slightly lower than the nationwide prevalence (6.92\%) and much lower than the state of Texas prevalence $(11.84 \%)$ among Medicaid pediatric patients. ${ }^{5}$ A plausible reason for the observed difference could be because in our study only $49.95 \%$ of the beneficiaries with at least 1 asthma medication during the study period had continuous enrollment. Therefore, we may have lost several patients who would have fulfilled the persistent asthma definition because of enrollment gaps. Also, in our study, persistent asthma was defined by the use of at least 1 controller medication. Therefore, failure to prescribe or patients not going to the pharmacy to fill their controller prescriptions could have underestimated the true prevalence of persistent asthma.

In our study, pediatric patients with persistent asthma had a median number of 7 asthma medications dispensed per beneficiary after the index date, suggesting better pharmaceutical care continuity than the overall asthma group. There was no statistically significant difference in the likelihood of receiving PCI interventions among patients with persistent asthma by age group, sex, or the median number of asthma medication claims during the study period. However, beneficiaries who visited the same pharmacy to get their asthma medications were more likely to receive PCI program interventions than those who visited more than 1 pharmacy $(P=0.027)$. The previous finding suggests the importance of creating a consistent patient-pharmacy rapport to increase the likelihood of implementing cognitive services interventions.

The mean AMR for beneficiaries with persistent asthma was 0.50. Based on the estimated AMR, it is reasonable to suggest that Medicaid pediatric patients with persistent asthma in Texas HSR 11 may be at high risk for poor asthma control, nonadherence, and increased incidence of hospitalizations or ED visits. ${ }^{22-24}$ This finding suggests a window of opportunity to optimize asthma therapies among pediatric patients with persistent asthma.

A potential tool to improve AMR among patients with persistent asthma is the promotion of $\mathrm{PCI}$ interventions when patients or their caregivers pick up their asthma prescriptions. In our study, pediatric patients receiving asthma PCI interventions had a higher AMR (0.530) than those without interventions (0.483). However, only 52 (0.76\%) beneficiaries with persistent asthma received at least 1 asthma PCI intervention after the index date. Although the AMR difference by PCI intervention was not statistically significant, the findings may have clinical relevance. Previous studies have reported that AMRs $\leq 0.510$ are associated with more than double asthma-related utilization rates than AMRs $\geq 0.530 .^{23}$

In our study, the total utilization of PCI interventions was suboptimal. Educational and promotional interventions to increase awareness of the PCI programs in Texas HSR 11 should be implemented to increase PCI interventions in network pharmacies. Future studies should be powered to measure if there is a statistical association between PCI interventions and improved AMR values. Using the same pharmacy to get all asthma medications was associated with higher mean AMR values than using more than 1 pharmacy.

Patients with persistent asthma who visit the same pharmacy to get their asthma medications may be more likely to interact with the pharmacy staff about their condition and subsequently experience better AMRs. Being in the school-age group was associated with higher AMRs. The Texas Education Code requires students with asthma or their caregivers to submit medical evaluations to justify the use and storage of medications on school premises. ${ }^{25}$ This public policy promotes the interaction between patients, caregivers, primary care providers, and school nurses, which may lead to better prescribing habits, utilization patterns, and AMRs.

The monthly number of pharmacy claims for asthma pharmacotherapies during 2018 and 2019 was used to describe asthma medication utilization trends among the MCO beneficiaries. The month of January showed the highest use, whereas June and July showed the lowest use for both years. When asthma medication utilization trends in our study were compared with asthma exacerbation trends reported in previous studies, ${ }^{26,27}$ it seemed that asthma medication utilization peaks occur 1 to 2 months after the peak months for asthma exacerbation episodes. The increase in asthma medication utilization in January correlates with the back-to-school season after the winter break. Influenza virus, human coronavirus, and human 
respiratory syncytial virus peak in the winter months when children return to school..$^{28}$ The viral infections may lead to asthma exacerbation episodes, which may increase the need for asthma medication restocking at home and school. Another interesting finding from the trend analysis is that persistent asthma cases generated $64.35 \%$ of the total asthma claims during 2019.

\section{LIMITATIONS}

This study has some limitations that need to be highlighted. Pharmacy claims for asthma medications among beneficiaries with continuous enrollment during the study period were used to operationalize the case definition of persistent asthma. However, excluding asthmatics with pharmacy coverage interruption may have caused an underestimation of persistent asthma's true prevalence. Patients with asthma with inadequate access to pharmaceutical care may have also contributed to the underestimation of the true prevalence. The number of potential patients with asthma with coverage interruption was high (50.05\%). Therefore, it needs to be emphasized that persistent asthma's estimated prevalence is among beneficiaries with continuous enrollment. On the other hand, when relying on pharmacy claims to identify persistent asthma cases, an overestimation may occur because some asthma medication for children may be used for other respiratory disorders (ie, cystic fibrosis or bronchiolitis).

The use of pharmacy claims for controller medications to capture persistent asthma cases has been shown to have face validity. ${ }^{24}$ However, it should be noted that using pharmacy claims for controller medications does not correlate perfectly with the HEDIS criteria to identify persistent asthma cases. ${ }^{24}$ Persistent asthma cases identified with the definition of at least
1 controller medication that are not captured with the HEDIS criteria are most likely patients who have a claim for an asthma control therapy during an acute viral illness but do not have a recurrence. This potential bias was minimized in our study by reinforcing the criterion of at least 1 controller medication with at least 1 subsequent asthma pharmacy claim to be considered a persistent asthma case.

It is difficult to translate the impact of the pharmacist-led intervention described in this study into clinical success without access to medical, emergency, and hospital claims. Despite this limitation, we used the AMR as a proxy measure for clinical success. The AMR has been shown to be an excellent predictor of asthma-related ED visits, hospitalizations, and patient-centered asthma outcomes. ${ }^{15,16}$

Because of the study's descriptive nature and the anticipated large number of beneficiaries with persistent asthma in the pharmacy claims dataset, a sample size calculation to detect a minimum difference in the mean AMR by PCI intervention was not conducted. However, although the number of beneficiaries with persistent asthma was large, the number of beneficiaries who received at least 1 PCI intervention was small.

Also, no causal inference should be drawn between PCI and AMR because of the descriptive nature of this study. Multiple potential confounders, such as number of comorbidities, number of concurrent medications, socioeconomic status, and health care resource utilization, were not accounted for in our study. The lack of information on these variables may have biased our results.

Finally, the generalizability of findings is limited to similar subpopulations.

\section{Conclusions}

Despite a high use of asthma medications among Medicaid pediatric beneficiaries, pharmacists servicing this group are underusing PCI program interventions. An increase in the AMR among patients with persistent asthma receiving PCI interventions was observed when compared with those without PCI interventions. However, the difference was not statistically significant. Subsequent studies should include larger groups of beneficiaries receiving PCI interventions to establish the effect of $\mathrm{PCI}$ interventions on AMR before widespread implementation.

\section{DISCLOSURES}

This research project was supported by the Global Institute for Hispanic Health (GIHH) through research grant M1803961. The authors have nothing to disclose.

A part of this study was presented as a poster at the AMCP 2020 Virtual Annual Meeting and Exposition Meeting, April 21-24, 2020.

\section{ACKNOWLEDGMENTS}

The authors thank Ms. Phuong Phan for her contributions during the final manuscript preparation phase and Dr. Eunae Jeong, Dr. Taylor Tomasino, and Dr. Sarah Bermudez for their preliminary data analysis assistance. The authors also thank Mr. Dustin Sanchez for his technical support with the administrative claims data.

\section{REFERENCES}

1. Pollart SM, Elward KS. Overview of changes to asthma guidelines: diagnosis and screening. Am Fam Physician. 2009;79(9):761-67.

2. Nurmagambetov T, Kuwahara R, Garbe P. The economic burden of asthma in the United States, 2008-2013. Ann Am Thorac Soc. 2018;15(3):348-56. 
3. Global Initiative for Asthma. Pocket guide for asthma management and prevention. Updated April 2021. Accessed May 18, 2021. https://ginasthma.org/ wp-content/uploads/2021/04/MainPocket-Guide-2021-FINAL-WM.pdf

4. Centers for Disease Control and Prevention. Most recent national asthma data. 2020. Last reviewed March 30, 2021. Accessed May 14, 2021. https://www.cdc. gov/asthma/most_recent_national_ asthma_data.htm

5. Smith A, Serban N, Fitzpatrick A. Asthma prevalence among Medicaidenrolled children. J Allergy Clin Immunol Pract. 2019;7(4):1207-13.e4.

6. Medicaid.gov. November 2020 Medicaid \& CHIP enrollment data highlights. September 30, 2020. Last updated April 2, 2021. Accessed May 14, 2021. https://www.medicaid.gov/medicaid/ program-information/medicaid-andchip-enrollment-data/report-highlights/ index.html

7. Texas Department of State Health Services. 2016 child asthma fact sheetTexas. Office of Surveillance, Evaluation, and Research. Updated March 2016. Accessed October 14, 2020. https://www. dshs.texas.gov/asthma/Documents/2016Texas-Fact-Sheet Child-Asthma.pdf

8. Sleath B, Gratie D, Carpenter D, et al. Reported problems and adherence in using asthma medications among adolescents and their caregivers. Ann Pharmacother. 2018;52(9):855-61.

9. Kercsmar CM, Shipp C. Management/ comorbidities of school-aged children with asthma. Immunol Allergy Clin North Am. 2019;39(2):191-204.

10. Gillette C, Blalock SJ, Rao JK, Williams D, Loughlin C, Sleath B. Discussions between medical providers and children/caregivers about the benefits of asthma-control medications. J Am Pharm Assoc (2003). 2014;54(3):251-57.

11. Gildon BL, John B, Condren M, et al. Pharmacist-managed short-acting beta agonist refill service in a general pediatric clinic. J Am Pharm Assoc (2003). 2018;58(3):296-302.
12. Ndefo UA, Davis PN, Henry A. Effect of home-based asthma medication therapy management program on pediatric African Americans with uncontrolled asthma. J Am Pharm Assoc (2003). 2019;59(4):521-26.

13. Broder MS, Gutierrez B, Chang E, Meddis D, Schatz M. Ratio of controller to total asthma medications: determinants of the measure. Am J Manag Care. 2010;16(3):170-78.

14. Schatz M, Nakahiro R, Crawford W, Mendoza G, Mosen D, Stibolt TB. Asthma quality-of-care markers using administrative data. Chest. 2005;128(4):1968-73.

15. Schatz M, Zeiger RS, Vollmer WM, et al. The controller-to-total asthma medication ratio is associated with patient-centered as well as utilization outcomes. Chest. 2006;130(1):43-50.

16. Andrews AL, Simpson AN, Basco WT Jr, Teufel RJ 2nd. Asthma medication ratio predicts emergency department visits and hospitalizations in children with asthma. Medicare Medicaid Res Rev. 2013;3(4):mmrr.003.04.a05.

17. Stanford RH, Shah MB, D'Souza AO, Schatz M. Predicting asthma outcomes in commercially insured and Medicaid populations? Am J Manag Care. 2013;19(1):60-67.

18. Yong PL, Werner RM. Process quality measures and asthma exacerbations in the medicaid population. J Allergy Clin Immunol. 2009;124(5):961-66.

19. National Asthma Education and Prevention Program. Expert Panel Report 3 (EPR-3): guidelines for the diagnosis and management of asthma-summary report 2007. J Allergy Clin Immunol. 2007;120(5 Suppl):S94-138.

20. Texas Department of State Health Services. Child current asthma prevalence by Health Service Region (HSR), Texas, 2013. Office of Surveillance, Evaluation, and Research. 2013. Accessed October 15, 2020. https:// www.dshs.texas.gov/asthma/ Documents/2013-Child-CURRENTASTHMA-Prevalence-by-PHR.pdf
21. Dombkowski KJ, Lamarand K, Dong $\mathrm{S}$, Perng W, Clark SJ. Using Medicaid claims to identify children with asthma. J Public Health Manag Pract. 2012;18(3):196-203.

22. Bidwal M, Lor K, Yu J, Ip E. Evaluation of asthma medication adherence rates and strategies to improve adherence in the underserved population at a federally qualified health center. Res Social Adm Pharm. 2017;13(4):759-66.

23. Beck AF, Bradley CL, Huang B, Simmons JM, Heaton PC, Kahn RS. The pharmacy-level asthma medication ratio and population health. Pediatrics. 2015;135(6):1009-17.

24. Andrews AL, Brinton DL, Simpson KN, Simpson AN. A longitudinal examination of the asthma medication ratio in children with Medicaid. J Asthma. 2020;57(10):1083-91.

25. Texas Department of State Health Services. Guide to medication administration in the school setting. 2017. Accessed October 15, 2020. https://www. dshs.texas.gov/uploadedFiles/Content/ Prevention and Preparedness/schoolhealth/pdf/Med\%20Guide\%20for\%20 Schools\%209.2017.pdf

26. Castro CR, Tarabichi Y, Gunzler DD, Ayache M. Seasonal trends in asthma exacerbations: are they the same in asthma subgroups? Ann Allergy Asthma Immunol. 2019;123(2):220-22.

27. Silverman RA, Stevenson L, Hastings HM. Age-related seasonal patterns of emergency department visits for acute asthma in an urban environment. Ann Emerg Med. 2003;42(4):577-86.

28. Moriyama M, Hugentobler WJ, Iwasaki A. Seasonality of respiratory viral infections. Annu Rev Virol. 2020;7(1):83-101. 